\title{
O CONTO, DA TRADIÇÃO À CONTEMPORANEIDADE: UM EXEMPLO EM LUIZ VILELA
}

Yvonélio Nery Ferreira ${ }^{1}$

\section{APONTAMENTOS INICIAIS}

O conto é uma forma literária que merece destaque, recebendo, ao longo da sua trajetória evolutiva, da teoria e da crítica literárias, diversos apontamentos. As atribuições e os estudos realizados nessas áreas sobre a "arte do conto" são inúmeros, desde sua origem - em um passado remotíssimo - até a contemporaneidade.

Considerada uma das formas literárias mais antigas, o conto é reconhecido como expressão de uma tradição narrativa de todas as culturas que fazem uso da linguagem oral ou escrita. Em alguns momentos da História, especialmente durante a Idade Média, o conto foi confundido com outras formas narrativas, como a novela e o romance, admitindo denominações tais como "história", "narração" e "fábula". No século XIX, muito embora o conto assuma um lugar de destaque junto ao romance, tornando-se, portanto, uma forma nobre. A partir da segunda metade desse século, o mercado editorial brasileiro passa a priorizar a publicação de renomados autores estrangeiros, cujas obras recebiam versões em Língua Portuguesa. Para fazer frente a essa concorrência, em certo sentido desleal, os autores brasileiros intensificavam suas produções literárias na modalidade romanesca, considerando que essa forma narrativa era a mais facilmente assimilada pelo público leitor ainda em fase de formação.

Já no início do século XX, apesar de ainda persistir a situação anterior, ou seja, o mercado editorial continuasse a privilegiar outras formas literárias, o conto passa a ocupar, no quadro geral da literatura brasileira, o lugar de destaque. Apenas para citar alguns dos mais representativos, autores como Mário de Andrade, Lygia Fagundes Telles, Clarice Lispector, Guimarães Rosa, Dalton Trevisan, José J. Veiga, Rubem Fonseca, Luiz Vilela, dentre tantos outros, fizeram desta forma narrativa um "modelo" pertinente às condições do leitor contemporâneo.

\footnotetext{
${ }^{1}$ Doutor em Literatura. Professor Adjunto III com dedicação exclusiva, na Universidade Federal do Acre, Campus Floresta, Cruzeiro do Sul, na área de Teoria Literária e Literaturas e Língua Portuguesa.
} 
Segundo Antonio Candido (1989, p. 210) "o conto representa o melhor da ficção brasileira mais recente, e de fato alguns contistas se destacam pela penetração veemente no real graças a técnicas renovadoras, devidas, quer à invenção, quer à transformação das antigas.”

Quanto à inovação, deve-se citar Rubem Fonseca, com seu ultra-realismo e novidades tanto na técnica, quanto nos temas. Na ruptura com esse realismo, tem-se a tendência do absurdo e a introdução do insólito, com José J. Veiga e Murilo Rubião. Ou seja, há um pluralismo nas modalidades de contos, tais como o fantástico, o psicológico, o regionalista, o social, o de costumes dentre tantos outros que constituem o rico panorama de estilos reunidos por essa forma literária.

Apesar de todas essas inovações, Antonio Candido, destaca o seguinte aspecto:

\begin{abstract}
Muitos autores mantêm uma linha que se poderia chamar de mais tradicional, sem dizer com isso que seja convencional, pois na verdade operam dentro dela com audácia - no tema, na violação dos usos literários, na procura de uma naturalidade coloquial que vem sendo buscada desde o Modernismo dos anos 20 e só agora parece instalar-se de fato na prática geral da literatura. Pode-se mencionar neste rumo a obra discreta de Luiz Vilela, escritor bastante fecundo que estreou em 1967 com um volume de contos (CANDIDO, 1989, p. 211).
\end{abstract}

Além de um histórico sobre o conto, desde seus primórdios até a contemporaneidade, passando por suas características estruturais, este artigo apresentará, como exemplo, aspectos concernentes ao conto de Luiz Vilela e o lugar assumido pelo autor na produção desta modalidade narrativa, procurando desvelar possíveis mudanças, além do que há de mais tradicional na narrativa do ituiutabano, fazendo-o figurar entre os melhores contistas da literatura brasileira.

\title{
HISTÓRICO: O CONTO DESDE OS PRIMÓRDIOS
}

Uma das hipóteses funcionais que justificam a antiguidade do conto é a do ato de contar e ouvir histórias. Essas atividades, desde tempos imemoriais, eram consideradas imprescindíveis à manutenção dos laços de união entre o homem e o grupo ao qual ele pertencia. Tal imprescindibilidade se fazia presente em inúmeras sociedades primitivas, pois significava uma forma de passagem dos mitos e, consequentemente, de toda ponte simbólica e ritualística de uma geração a outra.

$\mathrm{O}$ ato de contar está presente na oralidade de todas as sociedades do mundo, sendo considerado uma forma de manifestação dos anseios de criação do homem diante de sua realidade objetiva, que deve ser entendida como o mundo concreto que cerca o indivíduo; contrapõe-se à realidade subjetiva, que é a representação da realidade interior vivenciada pelos homens de modo 
geral e (re)criada pelo sujeito, para demonstrar a situação de "trânsito" entre o mundo objetivo e o subjetivo.

Essa prática tão cara ao sujeito é observada, inicialmente, na tradição oral, pois não há registros consistentes das primeiras manifestações escritas, além de Massaud Moisés (1982, p. 9) afirmar que o conto

[...] parece ter-se constituído em verdadeira matriz das demais fôrmas literárias. [...] ao menos deve ter sido matriz da prosa de ficção e, quem sabe, da própria historiografia”, ele pode ser considerado como "a mais antiga expressão da literatura de ficção.

O conto na sua forma escrita registra manifestações desde os egípcios, 4000 anos antes de Cristo, passando por histórias bíblicas, como as narrativas de Adão e Eva e a de Caim e Abel; pela cultura greco-latina, como a Odisséia e a Ilíada, além de outras que figuraram no Ocidente, vindas do Oriente, como As mil e uma noites (século X d. C.).

Scholes e Kellogg (1977) em um estudo intitulado A natureza da narrativa afirmam:

A literatura narrativa escrita tende a surgir em cena no hemisfério ocidental sob condições semelhantes. Emerge de uma tradição oral, conservando muitas das características da narrativa oral por algum tempo. Frequentemente assume a forma de narrativa heróica, poética, a que chamamos epopéia. Há, por trás da epopéia, toda uma variedade de formas narrativas tais como o mito sacro, a lenda quase histórica e a ficção folclórica, que se uniram numa narrativa tradicional, um amálgama de mito, história e ficção (SCHOLES E KELLOGG, 1977, p. 7).

Essa afirmação ratifica a origem do conto e de outras formas narrativas na oralidade, na tradição do ato de contar histórias. Ainda sobre esse aspecto, os teóricos complementam:

Para nós, o aspecto mais importante da primitiva narrativa escrita é o fato da própria tradição. O contador épico de histórias está contando uma estória tradicional. O impulso primário que o incita não é o histórico, nem o criativo; é recreativo. Ele está contando uma estória tradicional e, portanto, sua fidelidade principal não é ao fato, nem à verdade, nem ao entretenimento, mas ao próprio mythos - a história conforme foi preservada na tradição que o contador épico de histórias está criando. A palavra mythos significava exatamente isto na Grécia antiga: uma estória tradicional (SCHOLES e KELLOGG, 1977, p. 7).

$\mathrm{Na}$ Idade Média, as famílias se reuniam entre o jantar e a ceia para ouvir as novelas de cavalaria, de teor moralizador e religioso. Não havia uma definição literária, no que tange à forma, para essas histórias. Nesse momento, então, o conto era confundido com enumeração de relatos ou acontecimentos; fábula; apólogo; anedota; parábola; novela e romance - observados brevemente em comparação ao conto. Todas essas narrativas possuíam um caráter moralizador e religioso, uma vez que o homem era guiado pela teoria do Teocentrismo dogmático da Igreja Católica, que pregava um Deus punitivo, cujos ditames deveriam ser seguidos. 
Em face do processo histórico, o conto admitia confusões terminológicas, sendo largamente denominado de novela, apesar de sua forma já existir. Tal classificação perdurou até o século XVIII, quando lhe imputaram uma outra concepção. Segundo André Jolles (1976):

A partir do século XIV, aparece na Europa uma forma de narrativa curta a que se dá usualmente o nome de Novela e que é uma Forma artística. Segundo parece, teria sua origem na Toscana e, de qualquer modo, todo o desenvolvimento da Novela, foi decidido pela maneira como se apresentou pela primeira vez em Boccaccio (JOLLES, 1976, p. 188).

A obra Decameron de Boccaccio, lançada em 1350, é tida como aquela que lançou as bases clássicas do conto. Em Decameron as narrativas estão todas ligadas entre si por um ponto em comum. Essa estrutura recebeu, posteriormente, o nome de contos enquadrados.

Seguindo a mesma linha de Boccaccio surge, supostamente na Toscana, uma forma narrativa curta, que foi denominada novela toscana e, pouco tempo depois, já era escrita sob as formas de coletâneas ou ainda separadamente, dando ao texto um caráter autônomo. Ambas se espalharam por inúmeros países da Europa, sofrendo modificações, resultando em outras formas artísticas, mas mantendo uma definição identificável.

Quantitativamente, no século XVII, o conto passava por uma grande valorização produtiva, mas qualitativamente havia, segundo Massaud Moisés (1982, p. 17) "uma espécie de paralisia, de artificialismo", retirando do conto algumas características que só serão retomadas posteriormente, “trata-se, em suma, de um período de afetação e declínio, de que poucos escritores se salvaram”.

A palavra conto, até então, era utilizada por muitos, porém cada escritor a adotava por um prisma particular. Nesse ponto Jolles adverte (1976, p. 181): “O conto só adotou verdadeiramente o sentido de forma literária determinada no momento em que os irmãos Grimm deram a uma coletânea de narrativas o título de kinder-und Hausmärchen [Contos para Crianças e Famílias]”. Ou seja, a coletânea dos irmãos Grimm foi "a base de todas as coletâneas ulteriores do século XIX”.

Ao analisar o século XVIII, nota-se o mesmo marasmo qualitativo, e agora quantitativo na produção contística, provavelmente em decorrência de diversos fatos históricos, como a Revolução Francesa, motivadora de inúmeras reformas. Nesse ambiente, as produções valorizadas eram a poesia e a prosa doutrinária, ficando a ficção em prosa menos reconhecida, ainda que representada por grandes nomes, como Voltaire e Rousseau.

Passados os momentos de crise dos séculos XVII e XVIII, o conto conhece, no século XIX, um grande esplendor. Essa categoria narrativa deixa de ser apenas uma manifestação secundária e passa a assumir o caráter de nobreza entre as outras produções em prosa. Ao contrário dos 800, 
momento de parcos escritores da modalidade, o século XIX abarca autores de inigualável grandeza. Citando apenas alguns, na França destacam-se Balzac, Stendhal, Flaubert, Musset, Guy de Maupassant; na Alemanha, Ernst Theodor Wilhelm Hoffmann; nos Estados Unidos, Edgar Allan Pöe; na Rússia, Nicolai Gogol e Anatol Tchekov; na Inglaterra, Charles Dickens e Conan Doyle; em Portugal, Alexandre Herculano, Camilo Castelo Branco, Eça de Queirós.

Na literatura brasileira, há que se destacar a figura de Machado de Assis, não menos importante que os europeus. O escritor brasileiro produziu verdadeiras obras-primas, como "Missa do galo", "A cartomante", "Noite de almirante", "O alienista", além de tantos outros contos que figuram em sua vasta produção narrativa. Além de Machado de Assis, destacam-se, ainda, entre uma diversidade de escritores, as figuras de Aluísio de Azevedo, Afonso Arinos e Simões Lopes Neto.

No século $\mathrm{XX}$ - e procurando restringir as abordagens citadas à literatura brasileira - o conto não perde seu status, assumindo posição privilegiada, passando a ter um número imenso de produções que não comprometeram sua qualidade. Já na segunda década do século em questão, observa-se em Monteiro Lobato um grande contista do Pré-modernismo.

Lobato busca a popularização da obra literária, procurando a formação de um público leitor. Para tanto, abordava em seus textos tipos populares, caricaturais, com uma linguagem mais flexível, aproximando-se, inúmeras vezes, do coloquial, diferente do preciosismo comum aos escritores do século XIX e alguns do início do XX. Os contos de Lobato passam a ser vinculados em meios publicitários, causando polêmicas, como na criação do Jeca Tatu, no conto "Urupês".

O fim da primeira década do século passado foi marcado, na Europa, pela influência das ideias modernas e de vanguardas, como o Expressionismo, Cubismo, Dadaísmo, Futurismo e Surrealismo, tendo influenciado a literatura nacional, o que culminou na Semana de Arte Moderna de 1922. Esse momento favoreceu uma nova fase na produção contística, com autores como Mário de Andrade que, segundo Fábio Lucas (1989, p. 118) “é indiscutivelmente o grande contista a assimilar as formas novas e a encaminhar o relato segundo uma técnica de eliminação da distância entre o texto e o leitor". $\mathrm{O}$ autor modernista, além de contista também se tornou um teórico sobre o gênero, chegando a afirmar, ironicamente: "Em verdade, sempre será conto aquilo que seu autor batizou com o nome de conto." (ANDRADE: 1955, p. 5).

No dizer de Fábio Lucas (1989):

A afirmativa de Mário de Andrade, que se popularizou, levanta inicialmente o problema da impossibilidade de traçar limites formais ao gênero, embora se conheça a importância destes."

$[\ldots]$ 
$\mathrm{Na}$ verdade, a visão moderna do conto encarregou-se de despojar a narrativa curta de seu tratamento pomposo e prolixo, tratou de cortar uma floresta de verbosidade, desbastou a escrita de clichês mortos (LUCAS, 1989, p. 119, 120).

O conto é uma "narrativa que acompanhou a evolução da imprensa e das publicações periódicas" e "a revolução da imprensa e o uso cotidiano da palavra escrita veio modificar o gênero e fixar suas características básicas.” (LUCAS, 1989, p. 105 e 108). Tal fato ocorreu, no Brasil, a partir da implantação da imprensa, no século XIX - quando alguns escritos literários passaram a circular vinculados aos periódicos. Com a chegada da Família Real Portuguesa, em 1808, esse processo se intensifica e os folhetins passam a circular com publicações de contos, novelas e romances, o que perdurou até o início do século XX.

A partir da Semana de Arte Moderna, a produção contística toma um outro foco, diferente daquele com temáticas regionalistas prevalecentes até então. Provavelmente, essa mudança de olhar provém da inserção dos escritores num contexto urbano, impregnado de inovações - a cidade de São Paulo - que passou a representar, junto ao Rio de Janeiro, o centro cultural brasileiro, ditando a moda literária aos outros locais do País.

Essa movimentação do mundo moderno da metrópole paulista não será refletida apenas no enredo, mas, também, na utilização de uma linguagem inovadora. Segundo Antonio Hohlfeldt (1981),

A frase encurta-se, a comunicação deve ser mais breve, e, significativamente, incluem-se dialetos, sobretudo porque é em São Paulo que o número mais significativo deles se reúne, e é em São Paulo que as principais modificações sócio-político-econômicas se esboçam, desde a grande greve de 1917, passando pela explosão, no mesmo ano, dos anseios modernistas, num processo que desmembrará em diversas tendências estéticas, geradoras, por seu lado, dos movimentos políticos que se organizam no final da década, a partir da revolta tenentista de 1922, culminando na República Nova de 1930 (HOHLFELDT, 1981, p.62,62).

A geração de 1930 foi substancialmente romancista, com grandes escritores como Jorge Amado, José Lins do Rego, Graciliano Ramos, entre tantos outros representantes da prosa regionalista nordestina. Uma exceção foi Érico Veríssimo, que ambientou suas narrativas no Rio Grande do Sul.

A década de 1940, que, na História da Literatura engloba o fim da geração de 30 e o início da de 45, foi essencialmente poética, com nomes como João Cabral de Melo Neto, que lançou seu primeiro livro, Pedra do sono, em 1942, além dos concretistas, a partir de 1954. Apesar da primazia ao romance e à poesia nesse período, afirma Hohlfeldt (1981), ao apontar o período de 1930 a 1950: 
O conto, porém, espécie de substrato, continuou sendo praticado com tranquilidade, e nessas duas décadas surgiram esparsamente, os livros que, vistos da perspectiva de hoje, configurariam sua revolução, sobretudo a partir de Clarice Lispector, Samuel Rawet, João Guimarães Rosa e Murilo Rubião, abrindo cada qual um veio riquíssimo de exploração, que nos anos subsequentes seriam ampliados e aprofundados por eles mesmos ou pelos que se seguiram (HOHLFELDT, 1981, p.79).

Clarice Lispector inicia sua produção aos dezessete anos, surpreendendo a crítica pelo olhar dado às suas personagens. Principia com romances, Perto do coração selvagem, A cidade sitiada, A maça no escuro, mas desenvolve, também, inúmeras coletâneas de contos, como Laços de família, Onde estivestes de noite, Felicidade clandestina, A via crucis do corpo.

As personagens de seus contos são, geralmente, mulheres inseridas em um cotidiano aparentemente banal, imersas em situações configuradoras de alienação e com uma frágil consciência de si mesmas e do mundo circundante, em torno do qual gravitam. Aos poucos, esse cotidiano se revela perigoso, pois pode levar a personagem - a partir de experiências vivenciadas com objetos, animais ou pessoas - a um desvelamento de sua condição, fazendo-a adentrar um processo intenso de reflexão de si mesma e de sua condição como ser existente.

Ainda segundo Hohlfeldt (1981), Clarice Lispector insere-se na vertente do conto de atmosfera, pois:

[...] as personagens ocorrem e centralizam a atenção da narrativa, em outros momentos elas não são o cerne do conto. De qualquer maneira, o que guardamos de cada um destes escritores, de cada uma dessas obras, é justamente uma atmosfera, um clima, uma espécie de 'aura' que envolve a narrativa, tornando-a quase inconfundível: não importa qual personagem que aí surja, ela terminará envolvida por esta atmosfera (HOHLFELDT, 1981, p. 137).

Guimarães Rosa, por sua vez, dá início à sua produção contística em 1946, com o lançamento de Sagarana, obra com dez contos aclamados pela crítica. A partir de então, Rosa passaria, em definitivo, a ocupar lugar de destaque no cenário crítico nacional e internacional. Tal fato provém das inúmeras inovações observadas em suas obras, sempre dispostas a compreender a essência humana e ambientando-se num espaço rural e sobre ele refletindo, o sertão de Minas Gerais.

Esse interior mineiro, apesar de restrito, é tido pelo próprio escritor, como o mundo, ou seja, é um ambiente regional-universal, comportando, por meio da linguagem, os anseios das personagens, representação dos desejos do próprio homem. 
Pensando nisso, observa-se a linguagem como o elemento inovador e estruturador da obra rosiana. Inúmeras foram as novidades, dentre elas os neologismos, o aproveitamento da cultura popular, a metaforização do universo semântico e do falar do sertanejo, a prosa poética, dentre tantas outras representando, segundo Assis Brasil (1975, p. 79) “o próprio modo interior do personagem” e “como expressão do ato criador".

Nas décadas de 1960 e 1970, observa-se um grande número de escritores, como Rubem Fonseca, Osman Lins, Luiz Vilela, Moacyr Scliar, entre outros, fazendo o conto atingir significativa grandeza. Há, nos contistas dos anos 1970, um sentimento trágico, nefasto, afastando a possibilidade de comunicação das personagens diante de um mundo desestruturado e sufocante.

Segundo Hohlfeldt (1981):

\begin{abstract}
A década de 60 ficou conhecida, no Brasil, como a grande década do conto. Dezenas de escritores foram revelados ou solidificaram suas carreiras literárias através deste gênero específico, com especial destaque para os mineiros, que venceram praticamente todos os concurso então existentes. [...] Nos anos 1970, essa tendência em linha gerais permaneceu, embora o romance e a poesia tenham realizado uma rentrée razoavelmente boa no panorama literário nacional, e os anos 80 , pelo que se viu até agora, parecem prever uma nova solidificação do romance (HOHLFELDT, 1981, p. 12).
\end{abstract}

Apesar da reinserção do romance como modelo narrativo que passou a vigorar nas décadas de 1980 e 1990, o conto continuou a destacar-se, com escritores já conhecidos - da década de 1960 e 1970 - e escritores novos, participando da nova produção na virada do século XX, também chamada por Afrânio Coutinho (2003: p.275) de “A nova literatura e/ou o Pós-modernismo”.

Somando-se os escritores já conhecidos aos novos, tem-se na narrativa contemporânea nomes como os de Sérgio Sant'Anna, Jorge Mautner, Adriana Lisboa, Luiz Vilela, Luiz Ruffato, Antônio Carlos Viana Mangueira, além de tantos outros.

Em meio às várias tendências dessa nova narrativa, tem-se, por exemplo, a literatura e o debate com o realismo ou a espetacularização do real. Pode-se pontuar como característica desse tipo de produção a reinvenção da representação realista. Nessa perspectiva, nota-se uma forma de narrar exacerbadamente aproximada do real e compromissada com as descrições minuciosas e com os relatos.

Outra vertente refere-se à literatura da periferia e dos "Outros", cuja propensão abarca temáticas de uma literatura dita periférica como de autores presidiários desejosos de contar suas experiências nos cárceres. Essas são apenas duas das vertentes da produção da "literatura contemporânea", sobre as quais afirma Antonio Candido (1989): 
Há uma circunstância que nos faz refletir: a ficção procurou de tantos modos sair de suas normas, assimilar outros recursos, fazer pactos com outras artes e meios, que nós acabamos considerando como obras ficcionalmente mais bem realizadas e satisfatórias algumas que foram elaboradas sem preocupação em inovar, sem vinco de escola, sem compromisso com a moda; inclusive uma que não é ficcional. Seria um acaso? Ou seria um aviso? Eu não saberia nem ousaria dizer. Apenas verifico uma coisa que é pelo menos intrigante e estimula a investigação crítica (CANDIDO, 1989, p. 215).

Essa afirmativa sugere uma necessidade de questionar essa nova literatura, desejosa de inovações e teorização. Para tanto, é importante a postura do teórico da literatura, na fundamentação e na tentativa de compreender como se processam essas produções ficcionais.

Alguns autores, como Luiz Vilela, além de lançarem mão de certas inovações, conseguem manter um vínculo com a estrutura tradicional do conto - algo a ser discutido em um tópico exclusivo sobre o conto de Luiz Vilela. Agora, fazem-se necessários alguns apontamentos acerca da estrutura do conto, seus processos e elementos composicionais - aspectos que serão discutidos no próximo tópico.

\section{ELEMENTOS COMPOSICIONAIS}

Em sua evolução, o conto tem sofrido frequentes modificações, tanto em sua estrutura, quanto em sua classificação literária. Longo foi o tempo até essa forma narrativa adquirir o status que possui hoje. Anteriormente tido como expressão de menor grandeza, hoje atinge o patamar de gênero nobre, nos séculos XIX e XX.

Parcos eram os estudos aprofundados sobre a teoria do conto até o início do século XX. Pensando nisso, o crítico russo Vladimir Propp, com base no conto maravilhoso, decide aventurar-se no estudo desta forma narrativa, abrindo caminho para inúmeros outros teóricos, a partir do texto Morfologia do conto.

Crítica e autores são quase unânimes em teorizar o conto como um gênero de difícil tessitura, que exige um árduo trabalho de organização dos elementos que o caracterizam. No século XIX, Machado de Assis (1937, p. 45), um mestre do conto, em seu artigo "Instinto de nacionalidade", já afirmava essa dificuldade de classificação. Nessa perspectiva, o escritor e crítico observava o conto como "um gênero difícil, a despeito da aparente facilidade, e creio que essa mesma aparência lhe faz mal, afastando-se dele os escritores e não lhe dando, penso eu, o público, toda a atenção de que ele é muitas vezes credor". 
Nesta mesma linha, Julio Cortázar (2006) também aborda o conto como um gênero de classificações diversas, não possuindo elementos fixos, mas características mutáveis típicas de cada autor.

Ninguém pode pretender que só se devam escrever contos após serem conhecidas suas leis. Em primeiro lugar, não há tais leis; no máximo cabe falar de pontos de vista, de certas constantes que dão uma estrutura a esse gênero tão pouco classificável (CORTAZAR,2006, p. 150).

Para que se possa conduzir os estudos acerca das unidades composicionais do conto e buscando uma melhor compreensão de seus aspectos internos, uma comparação entre esse gênero, a novela e o romance poderá contribuir como um contraponto entre essas duas últimas formas narrativas e o conto.

Convém ressaltar que mesmo não fazendo parte dos objetivos deste trabalho apresentar uma análise histórica profunda da tradição narrativa no Ocidente, far-se-ão necessários alguns comentários acerca de certas características expressivas que marcam a trajetória narrativa do conto, inclusive com visões críticas de uma tradição escritural de autores modernos e contemporâneos.

Como já ressaltado, a Idade Média é o período no qual ocorreram as primeiras manifestações da novela. Obras como A queda do Santo Graal, de Gautier Map, escrita no século XII, foram fundamentais para a continuação da linhagem das novelas de cavalaria que perduraram até o século XVII. Durante esse período, nota-se o surgimento das novelas sentimentais, bucólicas e picarescas.

Nos séculos XVII e XVIII, a novela continua a ser cultivada, agora com alguns elementos do romance, momento de início do Romantismo. Nesse período romântico, a novela tornou-se um gênero de entretenimento, muito lido pela burguesia nos folhetins. Essa forma de divulgação foi utilizada em todo o século XIX e do XX, chegando até os dias atuais com seu formato televisivo.

Quanto à sua estrutura há, consecutivamente, cenas dialogadas, com processos de narração sucessivos, apresentando quadros comuns, com multiplicidade dramática. Segundo Jolles (1976, p. 192) a novela "se esforça por narrar um fato ou um incidente impressionante, de tal modo que se julgue estar na presença de um acontecimento real e ser esse incidente mais importante, aparentemente, do que os personagens que o vivem”. Portanto, a ênfase recai sobre a ação, com a progressão de vários núcleos dramáticos.

O romance, por sua vez, foi considerado durante muito tempo como um tipo nobre de narrativa, na qual há a predominância de acontecimentos simultâneos. Nessa sincronia, há certa atualidade e análise dos fatos, apresentados de forma analítica, no tempo e no espaço. Há, no romance, 
uma multiplicidade de ações com vários núcleos dramáticos e conflitos se desenvolvendo concomitantemente e exercendo influência mútua, um sobre o outro. Geralmente, o romancista estabelece um núcleo central, considerado o mais importante, unindo a ele outros secundários.

Teoricamente, o conto é uma forma na qual se busca a individualidade a partir de um prisma dramático único. Edgar Allan Poe, ao teorizar sobre o conto, aponta como elementos fundamentais para o gênero a intensidade, a brevidade e a unidade, a partir de um efeito singular. Esses componentes, que devem girar em torno de um só drama e polarizar-se em uma única direção, correspondem à forma pela qual a ação será exposta.

Para Julio Cortazar, o tema e sua abordagem levam à utilização de elementos essenciais para o desenvolvimento de um bom conto. Esse deve despertar, tanto no autor quanto no leitor, certa quantidade de sentimentos, de sensações e estabelecer relações com outras subtendidas na memória, chegando, então, ao status de "conto significativo", aquele que, no dizer de Cortazar (2006, p. 153) "quebra seus próprios limites com essa explosão de energia espiritual que ilumina bruscamente algo que vai muito além da pequena e às vezes miserável história que conta.”

Um conto significativo não precisa partir de situações grandiosas. A tendência do conto moderno é apresentar enredos com personagens inseridas em um cotidiano simples, com ações aparentemente banais. O tom elevado será dado pela forma segundo a qual o tema é abordado, despertando no espírito do indivíduo sensações e sentimentos diversos.

Ainda sobre os aspectos temáticos, Cortazar (2006) aponta:

\begin{abstract}
O que está antes é o escritor, com sua carga de valores humanos e literários, com a sua vontade de fazer uma obra que tenha um sentido; o que está depois é o tratamento literário do tema, a forma pela qual o contista, em face do tema, o ataca e situa verbal e estilisticamente, estrutura-o em forma de conto, projetando-o em último termo em direção a algo que excede o próprio conto. [...] Todo conto é assim predeterminado pela aura, pela fascinação irresistível que o tema cria no seu criador (CORTAZAR, 2006 p. 156).
\end{abstract}

$\mathrm{Na}$ estrutura do conto, o tema não é o único elemento composicional, pois espaço, tempo, personagens, trama, linguagem e ponto de vista são fundamentais para a compreensão da organização do espaço ficcional da forma narrativa em questão.

A visão tradicional teve uma contextualização própria, importante para a criação das teorias utilizadas por diversos pesquisadores, mas, ao pensar na literatura contemporânea, várias dessas proposições não são aplicáveis. O espaço, por exemplo, não representa mais um lugar restrito, mas, sim, um local, por vezes, impreciso, podendo ser ao mesmo tempo regional e universal, interiorano e 
cosmopolita; além de, muitas vezes, não indicar um espaço físico, mas sim um jogo de relações "espacializadas", em realidades que transitam entre o real e o abstrato.

Assim, o conto, como apontado por Machado de Assis e Júlio Cortazar, não se baseia em regras, sendo marcado pela ausência de leis. Um exemplo disso pode ser verificado em outro elemento composicional, o tempo, que, na contemporaneidade, rompeu com a visão tradicional, segundo a qual, os acontecimentos deveriam ocorrer em um curto espaço de tempo. Na contemporaneidade, o tempo, assim como o espaço, passa a ser indeterminado, e por vezes longo.

Por sua vez, a trama - vista tradicionalmente como lógica, objetiva, apresentando semelhanças com a vida real e uma cronologia mensurável - pode apresentar-se, também, de forma ilógica, desestruturada, não exercendo muita proximidade com o real. Um exemplo disso são os contos fantásticos, com enfoque em elementos nada convencionais.

A título de ilustração, lembra-se que o fantástico na literatura é expresso pela hesitação entre real e imaginário. Essa hesitação foi explicitada por Todorov (2007) como característica marcante da literatura desse gênero. A oscilação entre uma explicação racional e conhecida (consciente) e a aceitação irracional de um evento estranho às leis da natureza (inconsciente) acaba promovendo a simultaneidade desses aspectos. Além disso, para que exista a hesitação, é necessário que o leitor "participe" do texto e, ao mesmo tempo, perceba seu papel de receptor. Portanto o leitor não poderia interpretar o texto alegoricamente, o que o colocaria muito distante da narrativa, nem poeticamente, o que impediria o distanciamento necessário.

Todorov esclarece que, em muitos casos, a história fantástica, que nasce da coexistência de dois universos, dissolve-se em um dos pólos dessa tensão, característica que o crítico utilizou para sua classificação. O texto é dito fantástico-estranho, quando os acontecimentos insólitos são explicados de forma racional e essa explicação é aceita pelos personagens no mundo ficcional. Se os acontecimentos sobrenaturais afirmam-se como inexplicáveis, denomina-se o texto como fantásticomaravilhoso.

Outra característica da trama do conto moderno é a quebra de expectativas que levava o leitor a desvendar o mistério intrínseco a cada conto. Essa ruptura não faz o leitor perder o interesse pelos contos, pois esses continuam ocasionando sensações e sentimentos diante do cotidiano banalizado e esquecido pelo indivíduo ${ }^{2}$.

\footnotetext{
${ }^{2}$ Tal fato também ocorre no romance moderno.
} 
A linguagem, assim como os elementos já citados, é guiada pela objetividade e economia, não cabendo exageros nem floreamentos. O conflito essencial do conto pode ocorrer na fala das personagens, por meio do diálogo, elemento importante à estrutura desta forma narrativa.

Já o foco narrativo pode ser observado, tradicionalmente, de quatro formas. A primeira apresenta a personagem principal contando sua própria história, sendo denominado de personagemnarrador, utilizando, para isso, a primeira pessoa - do singular ou do plural - e a narrativa fica circunscrita à própria personagem. É um narrador limitado, do qual se deve duvidar, por possuir uma visão única dos fatos e por apresentar apenas um ponto de vista sobre os acontecimentos.

No segundo ponto de vista narrativo, uma personagem secundária conta a história da personagem central, mantendo um distanciamento entre o narrador e leitor, pois os fatos são contados por alguém distanciado do foco principal da narração, por uma terceira pessoa, que pode ter apenas presenciado os acontecimentos.

O terceiro tipo de ponto de vista é o do narrador com capacidade de capturar o mais íntimo das personagens, inclusive o seu psicológico, mas de forma limitada e imperfeita, por penetrar apenas nas camadas mais superficiais do subconsciente e do inconsciente. É um tipo de narração que se distancia do leitor.

O último tipo de foco narrativo apresenta um ponto de vista no qual o narrador se dedica, exclusivamente, a contar o que observou. Esse tipo de narrador não se intromete na história e seu ângulo de visão é superior ao do foco narrativo anterior. Ele é apenas um observador "que pode ver muito dentro dos limites de suas próprias deficiências de personalidade, inteligência etc.”, “tal enfoque suspende ou diminui a penetração psicológica em favor da ação, de modo a tornar a narrativa mais linear, menos complexa." (MOISÉS, 1982, p. 37).

Por sua vez, Silviano Santiago (1989) aponta como foco narrativo presente na contemporaneidade, o narrador pós-moderno:

Aquele que quer extrair a si da ação narrada, em atitude semelhante à de um repórter ou de um espectador. Ele narra a ação enquanto espetáculo a que assiste (literalmente ou não) da plateia, da arquibancada ou de uma poltrona na sala de estar ou na biblioteca; ele não narra enquanto atuante (SANTIAGO, 1989, p. 39).

A partir da visão de Santiago, nota-se o narrador pós-moderno como o típico ficcionista, pois ele tende a dar à narrativa uma veracidade própria, por não possuir a vivência dos fatos, o que lhes tira a autenticidade. Portanto, os fatos passam a ser uma construção da linguagem. 
O conto como uma forma narrativa não é composto somente a partir de sua estrutura, pois apresenta-se aberto, independente de sua extensão ou da presença desse ou daquele elemento em sua composição. Exemplos de textos que rompem com essa visão tradicional e simplista de apontar o número de páginas como importante na classificação da narrativa são os contos de Tutaméia, de Guimarães Rosa e o conto O alienista, de Machado de Assis.

Os contos de Rosa apresentam uma estrutura extremamente condensada, raramente irrompendo a barreira das quatro páginas; já o texto machadiano apresenta uma narrativa extensa. Repletos de inúmeras características divergentes da visão tradicional, o conto, como aponta Mário de Andrade, é aquilo que o autor quer que seja conto.

Portanto, espaço, tempo, personagens, trama, linguagem e ponto de vista são componentes estruturais, mas não imprescindíveis para fundamentar a teoria do conto, sendo apresentados no intuito de entender como se apresenta esse gênero narrativo tão cercado de controvérsias.

Após tais apontamentos, buscar-se-á apontar como se processam a linguagem e a organização dos diálogos, relevantes para a compreensão dos problemas existenciais que envolvem as personagens da trama contística de Luiz Vilela.

\section{O CONTO DE LUIZ VILELA}

O medo da solidão; a necessidade; a falta de comunicação, expressas a partir do diálogo e da introspecção; a linguagem simples; os contrapontos entre passado e presente, juventude e velhice são características imprescindíveis para a estruturação e compreensão dos contos de Luiz Vilela. Pensar esses subsídios narrativos é adentrar um mundo em que há um constante questionar da existência, marcada por momentos de extrema desilusão e incompletude dos anseios do homem.

É inegável e quase unânime entre a crítica reconhecer o diálogo como elemento fundamental na composição narrativa de Vilela, delineando não só um mero recurso estilístico, mas também uma forma de discutir questões existenciais. Portanto, o diálogo pode aparecer marcado tanto por travessões quanto por aspas. Em entrevista (Paniago, 2002), Vilela comentou:

Nem sempre tenho uma resposta clara, sinto que tem mais a ver usar um ou outro. Há sutis, mas importantes diferenças entre eles. Tem que ter fluência no desenvolvimento da narrativa. É como se um, o travessão, fosse uma subida, degrau por degrau, e o outro, as aspas, é mais seguido, tem menos breque. Não sei. O que posso dizer com certeza é que não é aleatória a escolha de um ou outro (PANIAGO, 2002, p. 2). 
Ambas as formas de diálogos apresentadas acima podem ser vistas possivelmente, como um meio, dentre tantos outros, de solucionar os problemas existenciais das personagens. A relação com o Outro - quando essa acontece - ocorre, por vezes, a partir de diálogos evasivos, indicando uma incapacidade de verbalização dos sentimentos. Pode-se supor que haja, nessa evasão, ou a busca de se dizer para o Outro ou a necessidade de se afastar dele, o que poderia indicar medo ou receio de sua visão.

Nessa perspectiva, Augusto Massi (2001, p. 17) afirma o diálogo, no âmbito da linguagem, como um elemento "sempre a serviço da comunicação. Mas, muitas vezes ele camufla o silêncio, denuncia o esvaziamento da conversa, a solidão dos que falam”. Pode acontecer de a personagem negar-se a utilizar o diálogo, levando o sujeito a uma introspecção, a um isolamento do mundo, incapacitando o diálogo e, consequentemente, a possibilidade de ter no Outro um mediador, aquele que estabelece conexões entre objetividade e subjetividade.

O conto "O buraco", de Tremor de terra, é uma demonstração do afastamento e da negação da comunicabilidade com o outro. José, ao cavar um buraco no quintal de sua casa, vai se isolando do mundo e de suas relações interpessoais, chegando ao ponto de passar a viver nesse buraco, não buscando nenhuma relação comunicativa com ninguém, após ter virado tatu.

Esse conto pode representar uma metáfora do indivíduo moderno, impossibilitado de estabelecer uma relação mais profunda com o Outro. Portanto, segundo Massi (2001):

Embriagados pela raiva e seduzidos pelo silêncio, os personagens parecem intuir que algo de verdadeiro e íntimo está se perdendo e tentam, num gesto desesperado de resistência, se agarrar a um individualismo feroz. Travam um exasperado diálogo consigo mesmo (MASSI, 2001, p. 13).

A relação dialógica, baseada no processo interacional eu - outro, está presente tanto no diálogo quanto em sua negação, fato que representa uma forma de se entender, de se dizer e de ser dito, no entanto, o medo da rejeição leva, por vezes, ao cerceamento dos diálogos. Isso é fundamental para se compreender as questões existenciais que envolvem as personagens.

Segundo Hohlfeldt (1981):

A verdade é que a estruturação de um conto de Vilela é sempre e basicamente a mesma: monologando (consigo e, consequentemente com o leitor, pois a consciência do ato de escrever - e em decorrência do de leitura por parte de um hipotético leitor) ou dialogando, as personagens de Luiz Vilela avançam com que às apalpadelas, mas com razoável segurança, em meio aos labirintícos elementos desconhecidos, em busca de uma verdade, ainda que extremamente particularizada. Assim, o texto se auto-reconhece e reconhece a seu narrador, desvendando sua não adaptação ao meio e consequente opção pela solidão, numa espécie de 
autoflagelação, cujo contraponto mais evidente são certas revelações antecipadas da trama que o texto, aqui e ali, realiza (HOHLFELDT, 1981, p. 199).

Também sobre o diálogo, Fábio Lucas afirma (1970):

[...] seus contos trazem profunda significação filosófica, apanham o homem mutilado por sua incapacidade de comunicar-se. Os seres não transmitem sua essência e sofrem, arruínam-se. A palavra torna-se um veículo imperfeito e enganador (LUCAS, 1970, p. 127).

Essa afirmação demonstra as conturbadas relações estabelecidas entre o homem, o cotidiano e o Outro, representadas na literatura contemporânea, assim como o sujeito, fragmentadas. Nessas relações, as personagens, na observação de Wilson Martins (2001, p. 9) "sofrem da condição de existir, da procura sempre frustrada de um sentido para o que acontece".

A linguagem é o elemento que irá representar as relações humanas presentes no diálogo. Há um coloquialismo entremeado nas narrativas, que indica tanto registros da vida contemporânea quanto um ritmo oral do falar do interior. Do fluxo da narrativa, parecida com prosa, observam-se as frases feitas, as conversas familiares, a vida na pequena cidade, rituais fúnebres, histórias que mais parecem "casos", características típicas da "mineiridade".

Para Wilson Martins (2001, p. 8)

[...] o estilo de Luiz Vilela estrutura-se em torno de frases simples e da notação rápida; ele é particularmente notável na espontaneidade com que reproduz não somente o diálogo, mas o tom da conversação, configurando um exercício discursivo no qual, a partir da linguagem, há o desenvolvimento de temas como a solidão, a nostalgia, o sofrimento humano, muitas vezes relativos a dois tempos: passado e presente, alimentando a retomada de valores éticos não mais adequados aos padrões atuais da sociedade (MARTINS, 2001, p. 8).

O tema da solidão pode ser observado em contos como "Luz sob a porta", de Tarde da noite e "Amanhã eu volto", de No bar. Ambos tratam do tema da velhice e de como essa favorece ao afastamento das pessoas. Como que por um processo de exclusão, o idoso é visto como aquele a quem se deva dedicar pouca atenção, um verdadeiro peso para a família. Nos dois contos a partir dos diálogos durante as visitas - no primeiro, do filho à mãe que completa 60 anos, e, no segundo conto, do neto à avó de 90, já meio surda e cega - nota-se esse apagamento ao qual o idoso vai sendo submetido. Nesse sentido, ansiedade, desconforto, sentimento de estar à deriva, problemas de comunicação entre as personagens são apenas alguns elementos importantes a serem observados nos contos de Luiz Vilela. 


\section{APONTAMENTOS FINAIS}

A partir dos apontamentos apresentados neste artigo, a respeito do conto, as observações sobre o espaço ficcional impuseram uma abordagem teórico-crítica acerca desta forma narrativa, visando a identificar, na sua trajetória evolutiva, o reconhecimento de como essa modalidade literária se configura no tempo. Portanto, recorreu-se ao estudo da estrutura do conto e de seus elementos composicionais, respeitando as suas distintas particularidades.

No que diz respeito ao histórico, observou-se certa dificuldade ao tentar uma definição de conto de forma a precisar a sua função e a sua estética narrativa. Por isso, considerou-se várias as suas possibilidades de classificação. Observou-se, por exemplo, que o estudo do conto não contempla critérios de quantidade em oposição à qualidade, isso é, não é a sua extensão que assegura a sua importância literária. Trabalhado desde tempos imemoriais, quando ainda era tido como narrativas orais, chegou-se à posição de que o conto passou pelas diversas áreas da história da literatura, ora tendo mais destaque, ora sendo tratado como um gênero menor, mas que assume na contemporaneidade o status de "grande forma literária".

Outro aspecto relevante deste estudo foi a abordagem das características do conto de Luiz Vilela, cuja estrutura composicional enfatiza personagens complexos. Esses, a todo momento, induzem o leitor a reflexões acerca das relações humanas, em que o diálogo, ganha força, até mesmo por oposição. Ou seja, quando temática recai sobre o silêncio, a busca de sentido para o non sens do mundo continua a exigir interpretações plausíveis que tornem a existência suportável. Tanto os diálogos quanto os monólogos são recursos utilizados pelos personagens, que refletem sobre sua condição no mundo, sem consciência do significado de que o homem é um ser em circunstância.

\section{REFERÊNCIAS:}

ASSIS, Machado. "Instinto de nacionalidade”. In: Crítica Literária. Rio de Janeiro, São Paulo, Porto Alegre: W.M. Jackson inc., 1937.

BRASIL, Assis. A nova literatura III - O conto. Rio de Janeiro: Companhia Editora Americana/MEC, 1975.

CANDIDO, Antonio. A educação pela noite \& outros ensaios. 2. ed. São Paulo: Ática, 1989.

CORTÁZAR, Julio. Valise de cronópio. Tradução de Davi Arriguci Jr. E João Alexandre Barbosa: organização Haroldo de Campos e Davi Arriguci Jr. 2. ed. São Paulo: Perspectiva, 2006.

COUTINHO, Afrânio. A literatura no Brasil. Vol. 6. São Paulo: Global, 2003. 
HOHLFELDT, Antonio Carlos. Conto brasileiro contemporâneo. Porto Alegre: Mercado Aberto, 1981.

JOLLES, André. Formas simples: Legenda, Saga, Mito, Advinha, Ditado, Caso, Memorável, Conto, Chiste. Tradução de Álvaro Cabral. São Paulo: Cultrix, 1976.

JÚNIOR, R. Magalhães. A arte do conto: sua história, seus gêneros, sua técnica e seus mestres. Rio de Janeiro: Bloch, 1972.

LUCAS, Fábio. Do barroco ao moderno: vozes da literatura brasileira. São Paulo: Ática, 1989.

LUCAS, Fábio. O caráter social da literatura brasileira. Rio de Janeiro: Paz \& Terra, 1970.

MARTINS, Wilson. "Música de câmara". In: Os melhores contos de Luiz Vilela. São Paulo: Global, 2001.

MASSI, Augusto. "Variações em torno de Luiz Vilela". In: Histórias de família, de Luiz Vilela. São Paulo: Nova Alexandria, 2001.

MOISÉS, Massaud. A criação literária: prosa. 4. ed. São Paulo: Cultrix, 1982.

PANIAGO, Paulo. Frases matemáticas; Turbilhão de lâminas certeiras. Correio Braziliense, 2 ago. 2002. Caderno Cultura.

SANTIAGO, Silviano. Nas malhas das letras. São Paulo: Companhia das letras, 1989.

SCHOLES, Robert e KELLOGG, Robert. A natureza da narrativa. Tradutor: Gert Meyer, revisor técnico: Afrânio Coutinho. São Paulo: McGraw-Hel do Brasil, 1977.

TODOROV, Tzvetan. Introdução à literatura fantástica. São Paulo: Perspectiva, 2007. 


\section{O CONTO, DA TRADIÇÃO À CONTEMPORANEIDADE: UM EXEMPLO EM LUIZ VILELA}

Resumo: O objetivo deste artigo é apresentar aspectos diversos que caracterizam o conto. Para tanto, inicialmente será exposto um histórico evolutivo dessa forma narrativa, desde seus primórdios até a contemporaneidade. Posteriormente, serão identificados elementos que compõem sua estrutura e como a mesma varia de tempos em tempos. Por fim, a narrativa de Luiz Vilela, um dos principais contistas brasileiros, servirá de subsídio para exemplificação das teorias até então abordadas. A base teórica será pautada em pressupostos de Candido (1989), Santiago (1989), Cortázar (2006), Todorov (2007), entre outros críticos.

Palavras-chave: Teoria do conto. Tradição. Contemporaneidade. Luiz Vilela.

\section{THE TALE, FROM TRADITION TO CONTEMPORANEITY: AN EXAMPLE IN LUIZ VILELA}

Abstract: The aim of this article is to present several aspects that characterize the tale. Therefore, initially an evolutionary history of this narrative form will be exposed, from its beginnings to the present time. Later, elements that make up its structure will be identified and how it varies from time to time. Finally, the narrative of Luiz Vilela, one of the main Brazilian short story writers, will serve as a subsidy to exemplify the theories hitherto addressed. The theoretical basis will be based on assumptions of Candido (1989), Santiago (1989), Cortázar (2006), Todorov (2007), among other critics.

Keywords: Narrative theory. Tradition. Contemporaneity. Luiz Vilela.

\section{EL CUENTO, DE LA TRADICIÓN A LA CONTEMPORARYIDAD: UN EJEMPLO EN LUIZ VILELA}

Resumen: El objetivo de este artículo es presentar varios aspectos que caracterizan el cuento. Por lo tanto, inicialmente se expondrá una historia evolutiva de esta forma narrativa, desde sus inicios hasta la actualidad. Más adelante, se identificarán los elementos que componen su estructura y cómo varía de vez en cuando. Finalmente, la narrativa de Luiz Vilela, uno de los principales escritores de cuentos brasileños, servirá como un subsidio para ejemplificar las teorías abordadas hasta ahora. La base teórica se basará en los supuestos de Candido (1989), Santiago (1989), Cortázar (2006), Todorov (2007), entre otros teóricos.

Palabras clave: Teoría del cuento. Tradición. Contemporaneidad. Luiz Vilela.

Submetido em Julho de 2019

Aprovado em Novembro de 2019 